\title{
LA AMBIGUA ESCRITURA DE SIMONE DE BEAUVOIR ${ }^{1}$
}

\author{
Olga Grau Duhart \\ Universidad de Chile \\ ograu_2000@yahoo.com
}

\begin{abstract}
Resumen / Abstract
Interesa en este artículo señalar las relaciones entre filosofía y literatura que pueden derivarse de la escritura de Simone de Beauvoir, quien realiza un aporte a la reflexión contemporánea respecto de dichas relaciones. La propia escritura de Simone de Beauvoir, que de acuerdo a sus particularidades podríamos nombrar como 'escritura ambigüa', constituye una propuesta y una apuesta por superar o sobrepasar los límites en que una u otra, literatura y filosofía, pudieran quedar constreñidas a cumplir la realización de determinados rasgos indicados como propios de tales géneros discursivos. Sugiero el concepto de 'género reflexivo' para denotar la peculiaridad de la opción de Simone de Beauvoir, quien prueba, a momentos simultánea o secuencialmente, los géneros discursivos de la literatura de ficción, los relatos autobiográficos y la escritura ensayística que expresa de modo más sistemático, sin constituir sistema, sus especulaciones de carácter filosófico. En este texto se considera de modo particular la concepción de la novela por parte de Simone de Beauvoir, a la que le otorga, en un momento de su producción, una preeminencia valorativa.
\end{abstract}

Palabras Clave: filosofía, literatura, escritura, condición humana, existencia.

\section{The ambiguous WRITING OF SIMONE DE BEAUVOIR}

The aim of this article is to show the relationships between philosophy and literature that may derive from Simone de Beauvoir writing who makes a contribution to contemporary reflection regarding these relationships. Her own writing, which could be named as "ambiguous writing" due to its particularities, constitutes a proposal and a commitment to overcome or to exceed the limits that either literature or philosophy might impose to comply with the accomplishment of the specific features inherent to these discursive genres. I suggest the concept of "reflective genre" to denote the peculiarity of Simone de Beauvoir's option when applying, at times simultaneously or sequentially, the discursive genres of fiction, autobiographical stories and essays writing that express more systematically her speculations of a philosophical nature.

In this text, I consider her conception of the novel which she gives a high pre-eminence, in a period of her production.

KEY WORDS: philosophy, literature, writing, human condition, existence.

Este texto, escrito el año 2010, hace parte de los resultados parciales del Proyecto Fondecyt Regular N¹100237, "Filosofía, literatura y género: la escritura de Simone de Beauvoir", del que he sido investigadora responsable. 


\section{Las dos pasiones}

RA Desde temprano, Simone de Beauvoir adolescente, como lo confiesa ella misma en su ensayo "Literatura y metafísica", se vio confrontada a dos fuertes pasiones que prevalecerán durante su vida y que encontrarán a lo largo de su producción escritural formas de conciliación. Una de sus pasiones era leer novelas -más tarde sería también escribirlas; otra, la lectura de textos filosóficos -luego daría curso a sus propios ensayos. El "asombro vertiginoso" en medio de la fascinación y la seducción que le producía la lectura de las novelas y los textos filosóficos, le hace preguntarse en su juventud por el lugar de la "verdad", lo que podemos entender como la pregunta por la posición de la verdad con respecto al tiempo: si acaso la verdad se sitúa en la temporalidad del mundo en su concretud o en la "serenidad de cielo intemporal" (De Beauvoir 1965, p. 77) ${ }^{3}$.

Podríamos decir que una de las formas que adopta su proyecto global, o la “elección global" (De Beauvoir 1965, p. 112) ${ }^{4}$, su escritura, es la anulación de los límites de esas formas de concebir y sentir el tiempo y de referirlo distintivamente a través de las palabras. Simone de Beauvoir, en el despliegue de su proyecto de escritura, intentará lograr la supresión de los muros entre filosofía y literatura. A su juicio, el lenguaje de lo universal presente en la filosofía y el lenguaje de las particularidades de la vida expresada en la literatura no logran por sí mismos expresar la totalidad de

2 Este texto, fue publicado por primera vez en el año 1946 en la revista Les temps Modernes $\mathrm{N}^{\mathrm{o}} 5$, y luego publicado en conjunto con otros ensayos por la editorial Nagel de Paris en conjunto con otros ensayos bajo el nombre de L'Existentialisme et la Sagesse des Nations (1948). El ensayo referido arroja importantes luces sobre el modo de concebir la relación literatura y filosofía que Simone de Beauvoir plasma en su escritura, la que en esa fase de su producción tiene determinadas particularidades útiles a nuestro propósito de indagar en ese engarce, que habría, en su caso, que referirlo también a la cuestión del género sexual.

3 Utilizo la edición española de 1965 del libro de Simone de Beauvoir El existencialismo y la sabiduría popular, Buenos Aires: Siglo Veinte, 1965. Su título original: L'Existentialisme et la Sagesse des Nations (1948). El año de la referencia bibliográfica utilizada coincide con el año de publicación en español de su obra Para qué la acción (1965), traducción argentina del original Pirrhus et Cinéas (1944), la otra publicación a la que hago referencia. Como hago alusión a ambas, para diferenciarlas las indicaré en cada caso en nota a pie de página. Hay disponible otra traducción de L'Existentialisme et la Sagesse des Nations, que a mi juicio es mejor: Simone de Beauvoir, El existencialismo y la sabiduría de los pueblos (2009), Córdoba: Edhasa. Colección Los libros de Sísifo, que puede ser consultada.

4 En el texto referido, Para qué la acción (1965), en el acápite "Comunicación”, hace referencia a su amor por los libros y a su admiración por los escritores, como también a su deseo de escribir, que desde su infancia, todos juntos, se revelan como "un solo y mismo proyecto". La persistencia de ese deseo, como el amor y admiración señalados, serán manifiestos en toda la escritura de Simone de Beauvoir, a través de la cual, en sus distintas expresiones, se constituirá en una búsqueda: articular un lenguaje que diga la verdad de la existencia en sus dos dimensiones temporales, el tiempo de la apariencia de las cosas y el tiempo esencial de ellas. 
la condición humana. Es ésta la que constituye el interés predominante de la filósofa, condición que es pensada existencialmente y que le exige encontrar el lenguaje para su cabal comprensión.

Respecto de la pregunta de dónde se sitúa la verdad, si sobre la tierra o en la eternidad, es decidora la expresión que utiliza Beauvoir, expresión fuerte que da cuenta del modo singular en que se ve afectada en esa búsqueda desde muy joven: "Me sentía descuartizada". El carácter escindido, la división de su ser que metaforiza corporalmente, quedan referidos a dos aspectos de nuestra condición: la imaginación, en el caso de la ficción literaria que ofrece el mundo temporal, concreto, "poblado de figuras y acontecimientos singulares" y el rigor del intelecto, expresado en el pensamiento filosófico en su pesquisa del ser de las cosas. La fabricación de sistemas le parecía "vana" desde la lectura literaria, y desde la filosofía le parecía "fútil" el escribir novelas (De Beauvoir 1965, p. 77) ${ }^{6}$. Simone de Beauvoir intentará unir sus propios pedazos, sus pasiones, comprendiendo filosóficamente su producción literaria y se propondrá justificar en este texto, a mi modo de ver, desde su concepción existencialista, esta suerte de género reflexivo de concordia ${ }^{7}$, si se me permite llamarlo así, inscribiendo su gesto en lo que en su opinión sería una tradición existente en el intento de conciliar los dos aspectos de la condición humana.

Beauvoir piensa que hay una sola realidad y que "es en el seno del mundo que pensamos el mundo" (ibíd., p. 78). En la doble seducción que afecta a "los espíritus que son sensibles" a la ficción y al rigor filosófico, entre los cuales ella se cuenta sin duda, se entregará tanto a imaginar y ficcionar el mundo como a entenderlo de manera intelectual a través del acto de escritura.

Para Simone de Beauvoir, el sentido de un objeto no es captable por el puro entendimiento, el que solo se devela en la "relación global" que sostenemos con él

5 En El existencialismo y la sabiduría popular. Simone de Beauvoir utilizará la misma expresión de sentirse "descuartizada" en un texto autobiográfico, refiriéndose a su relación con el tiempo pasado y el tiempo del porvenir. Como puede verse, esta metáfora tiene una cierta relevancia, que se hace atractiva para trabajarla en algún otro momento.

6 En El existencialismo y la sabiduría popular.

7 El término "concordia" que utilizo aquí adquiere una cierta legitimidad a propósito de un enunciado que la misma Simone de Beauvoir expresa en sus Memorias de una joven formal, en que alude a que veía posible fundar en el corazón su concepción moral del bien y del mal. Dice Simone, refiriéndose a la "moral pluralista" que trata de defender en un momento ante Sartre: "Ésta me gustaba porque me permitía tomar mi corazón como árbitro del bien y del mal". Simone de Beauvoir, Memorias de una joven formal, Ediciones Debolsillo, 2010, p. 349 (el destacado es mío). Si bien el contexto es distinto, me interesa pensar que es el corazón (como metáfora habitual y recurrente del sentir) donde encuentra Beauvoir un punto de cruce entre aquello que se concibe como opuestos. En este caso, lo imaginario y lo racional. Esta consideración reclamará un tiempo de atención posterior, por cuanto podría dar pie a elaborar una perspectiva respecto de lo afectivo en Beauvoir, en el modo en que aparece en su producción. 
y que es, además del entendimiento, "acción, emoción, sentimiento" (ibíd., p. 79). Es necesario hacer notar que la relación global implica la dimensión de la acción, lo que tiene alcances para la misma escritura: la escritura entendida como acción, como realización de develamiento que incorpora el 'sentir comprensivo', por decirlo así. De ese modo, interpretando la posición de la filósofa, no puede haber intelección en sentido estricto, si no se capta la complejidad del existir en su propio movimiento, desde una interioridad subjetiva.

Simone de Beauvoir establece, en su ensayo Para qué la acción, que la propiedad de un objeto, el ser algo con propiedad mío, solo es posible en la medida en que reconozco en aquello mi propio ser, "que haya sido fundado por mí" en su totalidad, con "materiales propios". Y más definitivamente: "Lo que es mío, es, en primer lugar, el cumplimiento de mi proyecto" (De Beauvoir 1965, p. 18) ${ }^{8}$. De ese modo, su proyecto de escritura está indisolublemente ligado a sí misma, a la materia de su propia interioridad o subjetividad. Le pertenece su producción de escritura en el acto de decidir escribir, que afirma su deseo y que, al mismo tiempo, actúa la escritura, implicando de esa manera las dimensiones de inteligibilidad, afección y acción. "Es mío, pues, en primer término, lo que hago" (ibíd., p. 19).

Sus vivencias pasadas constituirán materiales propios de su escritura, los que a través de ésta cobran un sentido de pertenencia, otorgándoles, al mismo tiempo, podríamos decir, un porvenir". E incluso, en palabras de Simone: "aun los objetos que en el pasado no han sido míos porque no los he creado, puedo hacerlos míos creando algo sobre ellos" (ibíd., p. 19). Entonces, las experiencias y logros de otros, que llegan a través de los relatos orales o escritos, pueden llegar a constituirse, de ese modo, como "puntos de partida de mis propias conquistas" y ser transformadas. El acto creativo de escritura les da otra vida: el jardín "se hace mío desde el momento en que lo cultivo" (ibíd., p. 21).

A Beauvoir le apasionaba la filosofía, camino que habría seguido al sentirla como su "vocación profunda", aunque Mlle. Lambert no la hubiera alentado a ello, como lo afirma en Final de cuentas (De Beauvoir 1972, p. 20). Saber y expresar, formaron parte de su proyecto original "incesantemente retomado y fortalecido"; su libertad fue, en sus palabras, la prosecución de tal proyecto, comprometida "esencialmente en el

\section{En Para qué la acción.}

$9 \quad$ Especialmente ello ocurre en su escritura memorialista, que compondrá de manera predominante la forma favorita de Simone de Beauvoir desde fines de los años 50, con la publicación en el año 1958 de Memorias de una joven formal. Si bien el conjunto de la obra de Simone de Beauvoir nos permite ver de manera manifiesta su exploración permanente de distintos géneros discursivos, la escritura que dominará, finalmente, será la escritura memorialista. En ello podríamos ver un modo en que resuelve de manera óptima una condición de género reflexivo que relata sucesos y devenires que tuvieron lugar en el tiempo, pero que trascienden, suscitando importantes motivos de reflexión filosófica. La profundidad de ésta no puede sino ser próxima a la búsqueda de las palabras que de mejor manera pueden decir aquello que se quiere decir, lo esencial de la condición humana. 
aprendizaje de la escritura" (ibíd., p. 32) ${ }^{10}$, consagrándose finalmente a escribir a partir de lo que fue haciendo de sí misma, en "un acto nuevo (ibíd., p. 39). Ello constituirá su gran preocupación, y la escritura, al permitirle sustentarse económicamente con ella, le ofrecerá un dominio de sí con réditos para su autopercepción de mujer privilegiada ${ }^{11}$.

La fidelidad al proyecto original de conocer y escribir solo tiene parangón con su vínculo con Sartre; ambos aspectos los reconoce como aquello que confiere unidad a su vida y a lo que nunca estará dispuesta a renunciar. Leyendo a Simone de Beauvoir caemos en la cuenta de que tanto el conocer, enmarcado en el proyecto de revelar el mundo, como también el acto de escribir los concibe como una suerte de representación de sí misma, como materialización textual para existir no solo para sí sino también para otros: "hacerme oír por mis contemporáneos" será una expresión que tiene, entre otros aspectos, la connotación del deseo de ejercer un impacto en la existencia de los demás, de ofrecerles sus experiencias como "puntos de partida" para las propias situaciones que los otros deben trascender. El escritor, según Beauvoir, trata de establecer a través de la escritura una comunicación con otro "a partir de la singularidad de su experiencia vivida" (De Beauvoir 1972, p. 139) y sus libros los concebirá como "cosas existentes para otros, pero habitados por una presencia: la mía" (ibíd., p. 41). George Steiner da cuenta, desde el lugar del lector, de la significancia y poder de la lectura, señalando que en ésta se arriesga mucho: "Es dejar vulnerable nuestra identidad, nuestra posesión de nosotros mismos", en la medida en que otra presencia se introduce en nosotros y "no hay camino de vuelta" (Steiner 2003, pp. 26-27).

Las dos pasiones de Beauvoir, la filosofía y la literatura, se encontrarán no solo en la lectura ardiente y vertiginosa de textos literarios y filosóficos, sino como escrituras rebasadas por la pensadora en sus propios límites. Sus textos filosóficos contendrán siempre alusiones a la vida concreta de las existencias humanas; y, curiosamente, ejemplos de acciones y de modos de relacionarse las personas serán tomados de la vida real o de las

10 "Comprometí mi libertad esencialmente en el aprendizaje de la escritura. No era un tranquilo ascenso, como el que me llevó a la graduación en filosofía, sino un esfuerzo vacilante, con insistencias, retrocesos y progresos tímidos" (Final de Cuentas, 1972, p. 32).

11 Simone de Beauvoir se considera privilegiada y, podríamos decir que en sus textos trasunta el sentir de un individuo privilegiado, con una convicción tremenda de afirmación de la vida y de su realización existencial a partir del cumplimiento de su "proyecto esencial", la escritura. No tiene dudas, desde muy joven, de que era alguien y que haría algo. Afirma esta condición de privilegio en El segundo sexo, en el sentido de considerarse entre las mujeres "mejor situadas" (Simone de Beauvoir, El segundo sexo, Buenos Aires: Ediciones Siglo Veinte, 1965, p. 23), lo que les permitiría el "lujo de la imparcialidad" para plantearse la cuestión de la mujer. Para Geneviève Fraisse, a Beauvoir la palabra "privilegio" le es familiar. "Ese término lo empieza a utilizar a partir de la Introducción de El Segundo Sexo formando parte del vocabulario existencialista. Se emplea en singular y en plural, dice el lujo de una situación, y el límite de un lugar individual" (Geneviève Fraisse, El privilegio de Simone de Beauvoir. Buenos Aires: Leviatán, 2009, p. 10). Este término, el de "privilegio", será utilizado por Beauvoir como título de tres breves ensayos y en ocasiones en su escritura autobiográfica. 
obras de ficción escritas por otros, materiales que al parecer considera equivalentes si son capaces de decir la existencia. En la equivalencia de esos distintos órdenes (lo vivido y lo ficcionado) vemos una clave significativa para entender la condición filosófica peculiar de la escritura de Simone de Beauvoir, incluso más allá de su propio reconocimiento como filósofa. Es sabido que Beauvoir niega su posicionamiento como tal y deja ese lugar, el de la filosofía, a Sartre y a sus amigos filósofos, tomando distancia de lo que vendría a ser un modo de la filosofía, un modo de escribirla, diverso a su propia relación con la filosofía como disciplina. Alejandra Castillo propondrá reconocer a Simone de Beauvoir como filósofa y como antifilósofa en tanto Beauvoir rechazaría inscribir su escritura en la institución filosófica: "ser filósofa para Simone de Beauvoir implicará, forzosamente, salir de la disciplina para preservar su vocación en la escritura. Es por este éxodo o exilio autoimpuesto que Beauvoir puede ser retratada como filósofa y antifilósofa a la vez" (Castillo 2008, p. 39).

\section{Una cierta ventaja de la novela como escritura por sobre el tratado filosófico}

Se puede apreciar en la posición de Simone de Beauvoir, manifestada en el texto "Literatura y metafísica", un cierto privilegio de la novela por sobre la obra filosófica, entendida como sistema de ideas, en tanto la novela sería una evocación de "carne y hueso" de la existencia, revelando una presencia "cuya complejidad, riqueza singular e infinita desborda toda interpretación subjetiva". La novela diría de mejor manera la condición humana, en tanto imitaría la "opacidad, la ambigüedad, la imparcialidad de la vida", suscitando en el lector reacciones similares a las que tiene frente a acontecimientos vividos. Simone de Beauvoir, entonces, validaría la ficción novelística en su carácter analógico con la existencia misma, en cuanto dicha ficción despierta una especie de conmoción existencial que suscita reflexividad sobre ésa. La novela sería la restitución en un plano imaginario de la experiencia, la que, a juicio de la escritora, se presenta “antes de toda elucidación” (De Beauvoir 1965, p. 79) ${ }^{12}$. Llegará a decir en su texto que "solo la novela permite evocar en su verdad completa, singular, temporal, el surgimiento original de la existencia” (ibíd., p. 89).

Simone de Beauvoir está haciendo en este escrito una referencia al pensamiento existencialista que busca expresarse en tratados teóricos y en ficción; por su parte, ella ha escrito ya dos novelas, La invitada y La sangre de los otros, y también dos ensayos previos al texto que en este momento nos ocupa. Ve en este doble gesto de escritura el intento por "conciliar lo subjetivo y lo objetivo, lo absoluto y lo relativo, lo intemporal y lo histórico; pretende captar la esencia en el corazón de la existencia”. La novela no sería traducción en el plano literario de verdades filosóficas, sino la revelación de "un aspecto de la experiencia metafísica que no puede manifestarse de otro modo" (ibíd.) ${ }^{13}$.

12 En "Literatura y metafísica", en El existencialismo y la sabiduría popular.

13 El destacado es mío. 
La novela es, entonces, la expresión adecuada a la manifestación de tal experiencia en su carácter subjetivo, ambiguo, dramático, singular, que permite expresarla en su integridad, "tal como ella se devela en la relación viviente que es acción y sentimiento antes de hacerse pensamiento". Las preocupaciones filosóficas de Simone de Beauvoir son compatibles con lo que exige la escritura de una novela, efectuando una suerte de inclusión de la filosofía en la literatura, semejante a algunos de los textos que realizan otros existencialistas, entre los que habría que contar al mismo Sartre.

En un texto posterior a "Literatura y metafísica", que encontramos en La plenitud de la vida ${ }^{14}$, se consigna la prevalencia que le otorga en sí misma a la producción de mundos subjetivos ficticios.

"Evocando ese mundo ilusorio me parecía elevarme por encima de mí misma y penetrar en carne y hueso ${ }^{15}$ en el universo de los cuadros, las estatuas, de los héroes de las novelas. Llevaba conmigo en esa gloria los juncos de olor salado y los murmullos del viento; el estanque era real, yo también; pero la necesidad, la belleza de la obra que nacería de ese instante lo transfiguraban y yo tocaba lo irreal. Nunca proyectos de ensayos o de artículos me han dado esa exaltación; resucitó cada vez que me entregué a lo imaginario" (De Beauvoir 2006, pp. 109-110).

En ese mismo libro, Simone no se concede el lugar de filósofa, aunque afirma que la filosofía le daba "satisfacciones que no me cansaban nunca" (ibíd., 231). Después de hacer referencia a que el mismo Sartre valoraba en ella sus dotes para la comprensión de la filosofía, y que podía ser más rápida y precisa que él en sus lecturas de las doctrinas filosóficas, declara no reconocerse como filósofa en la medida en que no posee la inventiva propicia para ser creadora en la filosofía en tanto elaboración de doctrina o sistema. Reconoce, sin embargo, en ella misma su sentido crítico, sus facultades de asimilación y comprensión de una teoría considerándola "una realidad viva". Pese a sus dotes y pasión por la filosofía, afirma:

"Sin embargo no me consideraba una filósofa; sabía muy bien que mi desenvoltura para entrar en un texto venía precisamente de mi falta de inventiva. En ese terreno, los espíritus verdaderamente creadores son tan pocos que es ocioso preguntarme por qué no traté de ser uno de ellos: más bien habría que explicar cómo ciertos individuos son capaces de llevar a bien ese delirio concertado que es un sistema $y$ de dónde les viene el empecinamiento que da a sus premisas el valor de llaves universales" (ibíd.) ${ }^{16}$.

14 Simone de Beauvoir, La plenitud de la vida, Buenos Aires: Editorial Sudamericana, sello Debolsillo, 2006. Este libro es la traducción de La force de l'age, que publicó la autora en 1960.

15 Esta expresión, “carne y hueso", la utiliza Simone de Beauvoir en muchísimos escritos.

16 Destacado mío. 
Por el momento, omitiremos del texto citado una última frase, que transcribiremos más adelante, por abrir otro asunto que requiere ser tomado en consideración separadamente y otorgarle la relevancia que merece.

El texto arriba citado nos permite profundizar en la posición que adopta Beauvoir con relación a la disciplina de la filosofía, pero también en una manera de entender su propia reserva respecto de un modo de hacer filosofía que, de alguna forma, la deja fuera, sin la posibilidad de autoconcebirse como filósofa. Podríamos afirmar que distingue su propia pasión de saber, conocer, comprender -con sus correspondientes peculiaridades-, de la pasión que tendría los distintivos del "delirio concertado", del que son capaces los espíritus "verdaderamente creadores" que se propondrían construir sistemas. Si bien Simone, ya hemos visto, busca también en la filosofía lo intemporal y universal de la condición humana, pondrá más énfasis en la expresión de lo singular, de la singularidad de la existencia, que la escritura de ficción, autobiográfica y memorialista, le permiten construir de mejor manera. Delirio y empecinamiento de la voluntad aparecen aquí como los rasgos de la escritura de los filósofos ocupados de construir sistemas, que tienden a ceñir el conjunto de la realidad a determinadas premisas de pretendida validez universal. La distancia que toma Simone de Beauvoir respecto de ello es una distancia crítica de no reconocimiento de sí misma en ese modo de concebir el proyecto filosófico. Por una parte, reserva a los filósofos ese empeño, afirmando su condición de "verdaderamente creadores", pero considera al mismo tiempo sus creaciones sistémicas como delirios concertados. Aunque separada la noción de delirio que utiliza de cualquier connotación psiquiátrica, éste implica siempre un exceso, una idea excesiva que afirmada impositivamente puede dejar clausurada la comunicación y operar de una manera excluyente, no solo con relación a individuos sino también respecto de la consideración de matices, factores, variables en la comprensión de las cosas, en tanto se afirma un discurso que se cierra sobre sí mismo. Los sistemas, en una suerte de estructuración centrípeta, podríamos decir, dejan fuera lo que no puede acomodarse al centro articulador de los sentidos instituidos por los sistemas mismos. En las consideraciones que hace Beauvoir podríamos hasta evocar las innumerables asociaciones que se han hecho entre genio y locura, entre la 'verdadera' creación y el desvarío de la razón que pretende comprender totalitariamente el mundo.

En Memorias de una joven formal, Beauvoir declara su fascinación inmediata por Sartre, fascinación que por lo demás durará toda la vida. Tenía la convicción, desde el encuentro juvenil con él, de que Sartre haría "un día una obra filosófica de consideración". Delirante, podríamos decir. Y agrega "Pero no se facilitaba la tarea, pues no tenía la intención de componer, según las reglas tradicionales, un tratado teórico. Le gustaba tanto Stendhal como Spinoza y se negaba a separar la filosofía de la literatura" (De Beauvoir 2010, p. 349) ${ }^{17}$. Es decir, la "obra filosófica de consideración" requeriría, desde esa perspectiva, un cierto distanciamiento de la literatura. Beauvoir 
oscila, vacila, y advertimos en ella un zigzagueo en el cómo posicionarse frente a la filosofía y la literatura, en tanto modos de expresión de la comprensión de la existencia.

Michèle Le Doeuff respecto de la particular manera que tiene Simone de Beauvoir de vincularse con la filosofía, viendo en su relación con Sartre un indicio de esa opción, hace una afirmación que interesa a nuestros propósitos: Simone de Beauvoir habría sido "víctima de una metonimia y haber confundido la parte con el todo" (Le Doeuff 1993, p. 209). Es decir, interpretando esta afirmación, Simone confundió una manera de hacer filosofía, la de los filósofos "verdaderos creadores", como ha establecido ella según el texto anteriormente considerado, con la filosofía misma, excluyéndose de ella.

Si bien Beauvoir da muestras de su gran capacidad de comprensión filosófica en el círculo de filósofos varones -entre los que se cuentan Sartre, Merleau-Ponty, Paul Nizan, Raymond Aron, Georges Politzer-, pondrá en duda, a partir de lo que podríamos llamar como la 'escena Luxemburgo', sus capacidades como filósofa y parece dar una señal de sus dificultades para adherir a la filosofía como disciplina constructora de sistemas. Se ve en desventaja con respecto a sus amigos que le obligan, dice, a la modestia. Refiriéndose a Sartre, afirma:

"Era la primera vez en mi vida que me sentía intelectualmente dominada por alguien. (...) Todos los días, todo el día, me medía con Sartre y en nuestras discusiones él era el más fuerte. En el Luxemburgo, una mañana, junto a la fuente de Médicis, le expuse esa moral pluralista que me habría fabricado para justificar a la gente que quería, pero a quienes no hubiera querido parecerme: la destrozó. Ésta me gustaba porque me permitía tomar mi corazón como árbitro del bien y del mal; me debatí durante tres horas. Tuve que reconocer mi derrota; además yo había advertido, en el curso de la conversación, que muchas de mis opiniones descansaban sobre parcialidades, mala fe o aturdimiento, que mis razonamientos cojeaban, que mis ideas eran confusas. "Ya no estoy segura de lo que pienso, ni siquiera de pensar", noté desorientada. No ponía en ello ningún amor propio. Era mucho más curiosa que imperiosa, me gustaba más aprender que brillar" (De Beauvoir 2010, pp. 349-350).

Este mismo texto lo cita Le Doeuff, y relevará el hecho de que Simone de Beauvoir afirma muchas veces que "ha dejado la filosofía a Sartre" (Le Doeuff 1993, p. 205). Pese a una cierta inseguridad para la disciplina de la filosofía y su modestia confesada, Beauvoir tiene que haber experimentado de manera notoria el reconocimiento de sus pares masculinos, y no solo por sus éxitos académicos en el periodo en que participaba junto con Sartre en las postulaciones para la agrégation en filosofía, sino también en los permanentes encuentros intelectuales amistosos que sostenían. Es sabido que si bien Sartre obtuvo el número uno entre setenta y seis candidatos para la cátedra de filosofía en 1929, aventajó escasamente a Simone de Beauvoir, quien obtuvo el segundo lugar. Hubo miembros del jurado que dudaron si conceder el número uno a Sartre o a ella. 
Todos coincidían que "ella era realmente la filósofa", en palabras de Davy y Wahl (Cohen-Solal 2005, p. 111) ${ }^{18}$.

La frase que omitiéramos en un texto citado más arriba, y que tomaremos ahora para dejar abierto un problema, es la siguiente: "Ya he dicho que la condición femenina no predispone a ese género de obstinación" (De Beauvoir 2006, p. 23), refiriéndose a su relación con la creación filosófica en la que se pueden reconocer los rasgos de una cierta obstinación delirante por los universales.

Aquí encontramos un enunciado que no podemos dejar pasar, en el que se establece una relación entre género de discurso y género sexual, enunciado que requeriría ser considerado de manera más extensa en otra ocasión. Resulta sorprendente esta afirmación que podría estar sugiriendo la presencia de determinadas condiciones genérico-sexuales esenciales, de predisposiciones que inclinan espontáneamente a un modo de realizar algunas acciones (de escritura en este caso), afirmación que estaría de cierta manera denegando las elaboraciones de El Segundo Sexo, y su premisa fundamental: La mujer no nace, se hace, con todas las implicancias teóricas y prácticas que esa frase tiene.

Beauvoir, con ese enunciado, se acerca y anticipa a algunos de los planteamientos de la teoría de la diferencia sexual: las mujeres, o más bien la 'escritura femenina', no serían tan proclives a la institución de sistemas teóricos, sino más bien a escrituras que involucran un decir la existencia sin empecinarse en otorgar a sus aseveraciones el carácter de verdades universales, en tanto se reconocen como escrituras situadas ${ }^{19}$. Ello querría decir, también, que lo singular adquiere significación y que es desde lo singular y que no es sino desde allí desde donde debe ser hablado lo universal. El "universal singular", será uno de los conceptos más queridos de Beauvoir, el que desarrolla a partir de sus propias reflexiones en diversos momentos de su producción de escritura, relacionándose estrechamente este concepto con las búsquedas de su vocación filosófico literaria ${ }^{20}$.

18 Tomado de Annie Cohen-Solal, Sartre 1905-1980, (Barcelona: Edhasa, 2005, p. 111). En el libro de Hazel Rowley, Sartre y Beauvoir (Buenos Aires: 2007, p. 46), la autora refiere que, como se llegó a saber, el jurado debatió largamente entre darle el "premio" a Sartre o a Beauvoir, dada la impresión que se llevaron por la sólida argumentación de esta joven. Pesó en la decisión el hecho de que Sartre se presentaba por segunda vez.

19 Las elaboraciones desde la teoría feminista sobre el conocimiento situado o "saberes situados" (Donna Haraway), pueden ser también extendidas a esta forma de producción o creación que es la escritura.

20 Simone de Beauvoir, cuando se encuentra en tales cavilaciones, está en un periodo en que quiere escribir algo "serio". No se siente tentada a escribir sobre las ideas de un determinado pensador; le desagrada la figura discipular y tampoco quiere escribir novelas o fantasías "de pacotilla". Decide finalmente, en sus propios términos, tratar de "hacer sensible una verdad que había experimentado personalmente" (La plenitud de la vida, 2006, Buenos Aires: Debolsillo, p. 232), quería hacer relatos breves, rigurosos, limitándose a las cosas y a las personas que conocía. De allí se generaría, de acuerdo a su propio relato, su texto Primacía de lo espiritual. 
Desde las elaboraciones del feminismo de la diferencia sexual, Hélène Cixous ha postulado una escritura femenina, en oposición a la virilidad de la escritura masculina. En su texto "La risa de la Medusa", Cixous sostiene que "hay escrituras marcadas", y que la escritura masculina sería una escritura, salvo excepciones, donde ha imperado una "economía libídinal y cultural" en que se ha reproducido "el rechazo a la mujer", que ha hecho manifiesta la "oposición sexual" (Cixous 2004, p. 23). La mujer no ha podido tener $s u$ propia palabra y encontrar en ella la posibilidad de cambio transformatorio de su propia subjetividad.

Simone de Beauvoir, al igual que otras mujeres, entre las que se destaca el nombre de Virginia Woolf, afirmaron y marcaron la escritura de un modo que podríamos llegar a entender como 'escritura femenina' o como "escritura que inscriba feminidad", que en los términos que señala Cixous hay que entenderla fuera de la sinonimia femenino=mujer, en tanto muchas mujeres han escrito también en la factura de la escritura masculina. Se trata de implicar la risa que transgrede el orden simbólico instituido, risa como gesto esencial de desacato, tal como lo señalara Rosi Braidotti. Cixous considera que es preciso que las mujeres (se) escriban de manera insurrecta, dando lugar a una escritura nueva, en que el cuerpo "se haga oír", cambiando "las reglas del pasado" (ibíd., p. 25). Si bien Simone no utilizó el término del falocentrismo, de acuerdo a los desarrollos conceptuales que realiza en El segundo sexo, podríamos decir que coincidiría completamente con este texto de Cixous:

"Casi toda la historia de la escritura se confunde con la historia de la razón de la que es a la vez el efecto, el sostén, y una de sus coartadas privilegiadas. Ha sido homogénea a la tradición falocéntrica. Incluso es el falocentrismo que se mira, que goza de él mismo y se felicita" (ibíd., pp. 23-24).

Beauvoir, podríamos afirmar, habría encontrado una vía de escribirse, como cuerpo que se hace oir, arrancada de la "estructura superyoizada" en la que siempre se le reserva el "lugar de culpable" (ibíd., p. 25). Aprender a hablar y escribir el propio texto será el deseo de Beauvoir, quien radicalizará ese gesto optando por escribir sobre sí misma, siendo ella misma la materia de su escritura en sus memorias y relatos autobiográficos, que van a llegar a constituir su escritura favorita. Beauvoir se ríe, altera la lógica de las oposiciones que también alcanza a la habitual compartimentación de los géneros discursivos.

En Simone de Beauvoir encontraríamos una escritura de rebeldía que no sigue la linealidad o una ambicionada objetividad generalizada. No oculta tampoco su apasionada política sexual, en la que liga lenguaje, saber y poder, a riesgo de ser juzgada como histérica, como ocurriera con la publicación de El segundo sexo. A juicio de Kristeva, Simone de Beauvoir escribiendo, nos escribió a todas: "nosotras somos como "escritas" por ella, cuando la seguimos, discutimos o rechazamos" (Kristeva 2009, p. 12). 


\section{La escritura filosófica de Simone de Beauvoir}

Bien podría entenderse la escritura de Simone de Beauvoir, en sus más variadas formas, como escritura filosófica que erige un modo de entender la filosofía de manera muy particular y propia. Su ambivalente y conflictiva inscripción en el ámbito de la filosofía como literata o filósofa nos hace atractiva su escritura para indagar justamente en las relaciones entre literatura y filosofía, que, a nuestro juicio, pueden ser más estrechas de lo que habitualmente se las supone. Respecto de esto último, para Alain Badiou "en lo que podemos denominar "filosofías existenciales", la filosofía se vuelve una parte de la literatura”, lo que permitiría preguntarse por una suerte de inclusión de la filosofía en la literatura (Badiou 2007, p. 4).

Beauvoir realiza a través de su escritura literaria un conjunto de categorías estrechamente vinculadas a su filosofía existencialista, como son las de proyecto, destinación, situación, sobrepasamiento, libertad, liberación, trascendencia, ambigüedad, las que cobran sus particularidades con relación a su posición política sexual. Su escritura literaria de ficción es, de ese modo, inseparable del esclarecimiento de carácter filosófico que la anima, lo que podríamos reconocer en La invitada, La sangre de los otros, Los mandarines, La mujer rota, entre otras de sus novelas. Sus textos autobiográficos y memorialistas no se eximen tampoco de la presencia de tales conceptos. En ese sentido, se hace muy difícil distinguir literatura de filosofía en el proyecto de escritura de Simone de Beauvoir. Puestos desde el lado de la literatura, ésta nos parece filosófica, y puestos del lado de la filosofía ésta se nos muestra de una manera poco habitual con múltiples referencias a ejemplos concretos o, decididamente, a obras literarias pertenecientes a la literatura universal que le ofrecen 'figuraciones' de la existencia. Nos parece que Beauvoir hace una propuesta de pensar filosóficamente, que la sitúa más allá de las expectativas de una construcción de sistema filosófico, ofreciéndonos un 'género discursivo reflexivo' en todas sus manifestaciones escriturales. Habría que preguntarse por una suerte de zona intermedia que instituye Beauvoir entre filosofía y literatura, lugar de intersección en que su propia subjetividad es articulada y puesta en movimiento en decursos imaginarios o ficticios o en relatos definitivamente autobiográficos. Uno podría preguntarse sobre cuál es su modo de borrar los límites. ¿Se trataría de una fusión propiamente tal, como un modo de establecer la borradura de los dos ámbitos, el metafísico y el empírico? O más bien ¿se trataría de un encuentro oscilante, divergente, de trastornos, traslapos y zigzagueos entre conceptos e imágenes, palabras que nombran ideas o modos de concebir, pero que al mismo tiempo se apegan a las figuraciones de la existencia? Y ello en la novela, en el ensayo filosófico, en las memorias, en el Diario, en las cartas.

Beauvoir establece un diálogo con algunos de los conceptos de Husserl y de su amigo Merleau-Ponty, en cuanto considera la ficción literaria con el valor de concepto. Merleau-Ponty afirma que "todo cambia cuando una filosofía fenomenológica o existencialista se da por tarea, no explicar el mundo o de descubrir las condiciones de posibilidad, sino de formular una experiencia del mundo, un contacto con el mundo que precede todo pensamiento sobre el mundo (...). Desde entonces la tarea de la literatura y de la filosofía no pueden estar separadas (...). La expresión filosófica asume las mismas ambigüedades que la expresión literaria, si el mundo está hecho de 
tal suerte que no pueda ser expresado sino en "historias" y como puesto en la mira" (Decousu 2008, p. 184) $)^{21}$.

Se podría decir que la ficción aparece en Simone de Beauvoir como método de indagación filosófica, en tanto la escritura literaria es desafiada a revelar una particularidad de la experiencia humana, un modo de ser en el mundo, una singular manera de existir, una experiencia metafísica. En la escritura de una novela, Beauvoir se entregaría a descubrir en el mismo proceso de invención determinadas condiciones ontológicas del existente, de los existentes que cobran cuerpo a través de la trama narrativa. Su materialidad es la de la semejanza con la vida real, con la experiencia humana, y podríamos decir que algo más sabe Beauvoir sobre la existencia después de escribir sus libros de ficción. El proceso de indagación que se realiza a través de la imaginación y de la reflexión es parte de la reflexividad que un sujeto puede hacer desde las limitaciones y posibilidades de su propia vida actual. Límite en el ser y posibilidad de ser forman parte del movimiento del existir concreto, ya sea que se de éste en la ficción o en la realidad. En la novela, los personajes podrían seguir diversos derroteros, podrían ir en uno u otro sentido, y, como en la vida real, se ofrecerían distintas posibilidades a sus acciones futuras.

Los "núcleos filosóficos", de los que habla Badiou, y que encontramos en las novelas de Beauvoir, quedan expresados de manera encarnada. Podríamos hablar de una escritura filosófica que se ofrece literariamente no solo en la forma del ensayo sino también, y de una manera importante, en la forma de la ficción y de una escritura que es inseparable de su condición filosófica. Con ello podría resolverse la pregunta de si las novelas son funcionales a unos propósitos filosóficos o si son legítimos "documentos existenciales" (Badiou 2007, p. 67).

Badiou, examinando la relación literatura y filosofía en Sartre, sin considerar la que se encuentra en Beauvoir, afirma que éste utiliza la literatura de modo experimental en tanto "la literatura da el marco de una experiencia concreta y singular para verificar conceptos e hipótesis filosóficos" 22 . Badiou se está refiriendo a las elaboraciones

21 Cécile Decousu, "La philosophie du deuxième sexe. Cohérence du projet beauvoirienn, et au-delà", en: Julia Kristeva et al. (ed.), (Re)Dècouvrir l'oeuvre de Simone de Beauvoir. Du Deuxième Sexe à la Cérémonie des Adieux". Paris: Le Bord de l'Eau, 2008, p. 184. La traducción es mía.

22 En este punto me parece pertinente tener a la vista la conferencia de Alan Badiou "Filosofía y Literatura", donde establece un conjunto de acercamientos a dicha relación e invita a emprender otros análisis que permitieran ampliar el desarrollo que él mismo hace. Establece tres modalidades de comprensión de la relación entre filosofía y literatura que concibe como orientaciones: una de ellas es la literatura como objeto de estudio filosófico, es decir, se trataría de una orientación estética, en la medida en que la filosofía estudia la literatura desprendiendo categorías estéticas que permitan comprender el fenómeno literario (ejemplos que refiere: la Poética de Aristóteles para la comprensión de la tragedia; la República de Platón para el estudio de la poesía). La literatura es, en este caso, un objeto para la creación de conceptos que hacen posible el juicio o la comprensión. Otra orientación es la que "se 
que hace Sartre sobre Baudelaire y Flaubert, que serían "experimentos” (ibíd., p. 69) y, de acuerdo a esto, Sartre utilizaría la literatura como documento. El concepto de "verificación", no sería aceptable en Simone de Beauvoir respecto de su búsqueda particular, en tanto, a su juicio, en la novela existencialista se darían rasgos propios:

"No se trata aquí para el escritor, de explotar en un plano literario verdades previamente establecidas en un plano filosófico, sino manifestar un aspecto de la experiencia metafísica que no puede manifestarse de otro modo: su carácter subjetivo, singular, dramático y también su ambigüedad" (De Beauvoir 1965, p. $89)^{23}$.

En Final de cuentas, Simone de Beauvoir se referirá a otro aspecto que considera como una de las tareas esenciales de la literatura y lo que la vuelve "irreemplazable": "superar esta soledad que nos es común a todos y que sin embargo nos vuelve extranjeros unos a otros" (De Beauvoir 1972, p. 144). Esto podría entenderse tanto desde el lugar de lectora como del de escritora, y en este último aspecto Beauvoir no parece siempre tener en cuenta a sus lectores. Para ella el borroneo de frases en periodos difíciles de la vida, "aunque no las vaya a leer nadie", le permite superar el problema particular que le aqueja comunicándose "con toda la humanidad" (ibíd.). Es decir, la comunicación no se da necesariamente en tanto el otro acceda a la textualidad de su experiencia, sino en tanto su escritura toca en algún punto a toda existencia humana, en la medida en que en ese mismo punto da cuenta de ella.

Por otra parte, una obra literaria permite "salir de uno mismo, y toda mudanza me encanta" y ello podría reconocerse tanto en el placer que le ofrece a De Beauvoir la lectura como la escritura misma (ibíd., p. 145). En este libro, que está impregnado de la conciencia de la edad avanzada y que sigue avanzando, la filósofa expresa no querer renunciar "a esta impresión exaltante que por momentos me ofrece la literatura:

pregunta cuál es la acción de la literatura sobre la filosofía” y, en este caso, la literatura no es un objeto de estudio, sino "una suerte de condición de la filosofía" (ibíd., p. 41) e interesa la acción que ejerce la literatura sobre el pensamiento (la historia de la tragedia y su influencia en el nacimiento de la filosofía desde la perspectiva de Nietzsche o el poema como forma del pensar que da a pensar, en Heidegger, o la lectura verdadera del poema de Mallarmé que le permite al mismo Badiou hacer un "progreso filosófico sobre una cuestión particular"). La relación entre filosofía y literatura es, entonces, genealógica; la literatura como genealogía de la filosofía. La tercera orientación es la de que la filosofía es parte de la literatura en una relación de inclusión (el relato biográfico en Kierkegaard forma parte de la demostración filosófica; la escritura subjetiva de Pascal como "parte sustancial de su voluntad explicativa y filosófica”, como asimismo la de Rousseau, la literatura no puede separarse de la "elucidación filosófica") (ibíd., p. 44). Y Badiou afirmará algo, que para nuestros propósitos de esclarecer la relación entre literatura y filosofía que hay en Beauvoir, nos es muy productivo: en "lo que podemos denominar "filosofías existencialistas", la filosofía se vuelve una parte de la literatura, y es por esa razón que hablo de una relación de inclusión" (ibíd., p. 45). En "Literatura y metafísica", en El existencialismo y la sabiduría popular. 
creándome a mí misma en la dimensión de lo imaginario, creando un libro". Sin embargo, por el tiempo transcurrido, la relación con la escritura se le hace más ambivalente que antes y, aunque necesaria, confiesa que puede prescindir de ella; no se siente ya a sí misma "cargada de una misión" (ibíd., p. 161). Este aspecto es significativo en la medida en que para Beauvoir la escritura ha sido su modo de existir; es como si la cercanía de la muerte, el fin de la existencia, le hace perder la dimensión estructurante que la escritura ha tenido en su vida.

"Experimento en carne propia lo que dije en La vejez: aún el progreso tiene en la última edad algo decepcionante: se avanza, sí, pero trabajosamente, y sin la esperanza de ir mucho más allá de lo que se ha hecho. Conservo, sin embargo, el deseo de seguir contando el mundo y mi vida" (ibíd., p. 161).

En La plenitud de la vida, un texto escrito con anterioridad, encontramos definido lo que entiende como su misión: "la misión mía era prestar mi conciencia al múltiple esplendor de la vida y tenía que escribir a fin de arrancarlo al tiempo y a la nada", en una suerte de confianza en sí misma y en el mundo y en la convicción de que a través de la escritura puede recrear al ser humano (De Beauvoir 2000, p. 15) ${ }^{24}$. Al salir de la juventud, se le hace una convicción de que escribiría libros y pensó que serían exclusivamente novelas: "a mis ojos ese género sobrepasaba a todos los demás" y tenía la impresión de que se convertiría ella misma en un personaje imaginario:

"tendría su necesidad, su belleza, su tornasolada transparencia; mi ambición apuntaba a esa transfiguración. Yo era sensible, todavía lo soy, a todos los reflejos que juegan en los cristales o en el agua; los seguía durante largo rato, curiosa y encantada: soñaba con desdoblarme, convertirme en una sombra que traspasaría los corazones y los poblaría" (ibíd., p. 382).

La escritura de Simone de Beauvoir amalgama, podríamos decir, tres diversos registros: el relativo a una concepción filosófica existencialista; el que refiere a un discurso

24 Llama la atención que en distintos momentos de La plenitud de la vida, Simone de Beauvoir utiliza la palabra "prestar", o tomar en "préstamo"-esto último en algunos textos autobiográficos-, que entendemos como tomar prestada la vida de los otros, la sangre de los otros y también de sí misma, para la construcción de sus relatos, de sus personajes. "Presté a mi segunda heroína, Renée, el rostro, la palidez, la frente ancha de la hermana del doctor A., a la que había conocido en Marsella" (LPV, 233). "Presté a Marguerite mi infancia en el curso Désir y la crisis religiosa de mi adolescencia" (LPV, 235). "Presté a Blomart ciertas emociones de mi infancia" (LPV572). "Hasta la voz que presto a mis héroes, la de Blomart sobre todo, me molesta" (LPV, 572). Y nos ha interesado, especialmente, la expresión en: "prestar mi conciencia al esplendor de la vida" (LPV, 15). En una de sus acepciones del diccionario, prestar es "dar de sí, extendiéndose", acepción que hace sentido cuando Simone de Beauvoir, en otros textos, declara entrar en la vida de los otros (como por ejemplo en Para qué la acción), impregnar con su materia otras subjetividades, en esa suerte de misión de entregar su propia perspectiva al mundo, para ser y prolongarse en él. 
emancipatorio de las mujeres y el alusivo a lo cotidiano que se inscribe tanto en la producción literaria de ficción o memorialista, como también en las citas en medio de sus análisis.

No es casual encontrar en los ensayos filosóficos de Simone de Beauvoir referencias a relatos literarios o documentos existentes, en la medida en que la vida de las personas está allí presente y que se basan, en sus modos particulares de hacerlo, en la observación de las circunstancias que los sujetos viven. La alusión constante a esas circunstancias otorga a su escritura un carácter de incardinación sustantiva y hace permanente evidencia del importante papel que juegan las narrativas en su reflexión filosófica.

Hay una suerte de transitividad entre la vida propia, lo imaginario y lo reflexivo en la escritura de Simone de Beauvoir, de modo que las escrituras que podrían ser determinadas como escritos autobiográficos, novelas y ensayos, quedan en ella en un juego que, si bien no elimina completamente sus adscripciones a los géneros discursivos reconocidos, logra cruces de significativa potencia en el despliegue de su modo de pensar el mundo y la condición humana.

Se ha señalado, y la misma Beauvoir lo hace, su mayor debilidad en la escritura literaria de ficción. George Steiner destaca el valor literario que tendrían las Memorias y dice de ellas que son "lo que hubieran debido ser sus novelas, maravillas de inmediatez física y psicológica” (Steiner 2003, p. 23). Y, podríamos agregar, de extraordinaria densidad reflexiva.

\section{Referencias bibliográficas}

Badiou, Alan (2007), "Filosofía y literatura", Justicia, Filosofía y literatura, Rosario: Homo Sapiens Ediciones, p. 4.

Castillo, Alejandra (2008), "Simone de Beauvoir filósofa, antifilósofa", Revista de Cultura Papel Máquina, Año 1, N¹: 39, Santiago de Chile.

Cixous, Hélène (2004), "La risa de la Medusa", Deseo de escritura. Barcelona: Reverso Ediciones SL, p. 23.

Cohen-Solal, Annie (2005), Sartre 1905-1980. Barcelona: Edhasa, 2005, p. 111.

De Beauvoir, Simone (1965), Para qué la acción. Buenos Aires: Ediciones Siglo XX, p. 112. Traducción de Pirrhus et Cinéas (1944).

(1965), "Literatura metafísica", El existencialismo y la sabiduría popular. Buenos Aires: Ediciones Siglo XX, p. 77. Traducción de L'Existentialisme et la Sagesse des nations (1948).

(1965), El segundo sexo. Buenos Aires: Ediciones Siglo Veinte, p. 23. Traducción de Le deuxieme sexe (1949).

(2000), La plenitud de la vida. Buenos Aires: Editorial Sudamericana, sello Debolsillo, p. 23. Traducción de La force de l'age (1960). 
(1972), Final de cuentas. Buenos Aires: Editorial Sudamericana, Final de cuentas, p. 20. Traducción de Tout compte faite (1978), Paris: Gallimard. 350 .

(2010), Memorias de una joven formal. Ediciones Debolsillo, pp. 349-

Decousu, Cécile (2008), "La philosophie du deuxième sexe. Cohérence du projet beauvoirienn, et au-delà", en: Julia Kristeva et al. (ed.), (Re)Dècouvrir l'oeuvre de Simone de Beauvoir. Du Deuxième Sexe à la Cérémonie des Adieux". Paris: Le Bord de l'Eau, p. 184. La traducción es mía.

Fraisse, Geneviève (2009), El privilegio de Simone de Beauvoir. Buenos Aires: Leviatán, p.10.

Kristeva, Julia, et al. (ed.) (2009), (Re)Dècouvrir l'oeuvre de Simone de Beauvoir. Du Deuxième Sexe à la Cérémonie des Adieux". Paris: Le Bord de l'Eau, p. 12.

Le Doeuff, Michèle (1993), El estudio y la rueca. De las mujeres, la filosofía, etc. Madrid: Ediciones Cátedra, p. 209.

Rowley, Hazel (2007), Sartre y Beauvoir. Buenos Aires: Editorial Sudamericana, sello Lumen, p. 46.

Steiner, George (2003), Lenguaje y silencio. Barcelona: Editorial Gedisa, pp. 26-27. 